\title{
Özofagus varis kanaması tedavisinde uygulanan endoskopik bant ligasyonunun çepeçevre tek sıra veya hedeflenmiş çoklu tarzda uygulanmasının karşılaştırılması
}

\author{
Comparison of endoscopic band ligation treatment patterns (circumferential single row or targeted \\ multi-band) for esophageal variceal hemorrhage
}

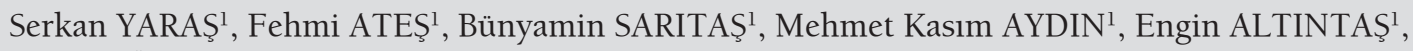
Gülhan ÖREKICI TEMEL ${ }^{2}$, Orhan SEZGIN ${ }^{1}$

Mersin Üniversitesi Tip Fakültesi ${ }^{1}$ Gastroenteroloji Bilim Dall, ${ }^{2}$ Biyoistatistik Ana Bilim Dall, Mersin, Içel

Giriş ve Amaç: Portal hipertansiyona bağlı gelişen özofagus varis kanamaları sirozun en ölümcül komplikasyonlarındandır. Bu kanamalarnn tedavisinde endoskopik bant ligasyonu en önemli seçenektir. Endoskopik bant ligasyonuna özofagus alt uçta, Z çizgisinin üzerinde, varislerin köken aldığı bölgeden başlanması önerilmektedir. Çoğu zaman hemodinamik açıdan sorunlu olan özofagus varis kanaması olgularına üst gastrointestinal endoskopide geçirilen sürenin kısa tutulması açısından az sayıda bantla endoskopik bant ligasyonu uygulamak daha faydalı olabilir. Çoklu bant sistemi ile varis ligasyonunun çepeçevre tek sıra halinde veya hedeflenmiş çoklu uygulanmasının etkinliğini karşılaştırmak amacıyla bu çalışma planlandı. Gereç ve Yöntem: Kliniğimize özofagus varis kanaması nedeniyle kabul edilen ardışı 39 hastaya rastlantısal olarak iki ayrı yöntemle endoskopik bant ligasyonu uygulandı. Böylece 19 hastaya çepeçevre tek sıra, diğer 20 hastaya da kolumnar hedeflenmiş çoklu tarzda endoskopik bant ligasyonu yapıldı. Cepeçevre tek sıra uygulamada her varis kolonuna $Z$ çizgisinin $2 \mathrm{~cm}$ üzerinden bir kez endoskopik bant ligasyonu uygulandı. Kolumnar hedeflenmiş çoklu uygulamada ise sadece büyük boyutlu ve üzerinde kanama işareti olan varis kolonu (veya kolonlarına) Z çizgisinin $2 \mathrm{~cm}$ yukarısından başlanarak alt uçtan yukarı doğru endoskopik bant ligasyonu uyguland. Ardından tüm hastalara Somatostatin $250 \mathrm{mcg} / \mathrm{saat}$ hızında intravenöz infüzyonu 5 gün uygulandı. Baveno V kriterlerine göre tedavi başarısı tekrar kanama, düzeltilmiş transfüzyon gereksinimi indeksi (Adjusted Blood Transfusion Requirement Index) açısindan değerlendirildi. Bulgular: Her iki grup, yaş ortalaması (54,35 yıla karşılık, 54.53 yıl, p=0.967), cinsiyet (K/E oranı \%100'e karşılık \%46,15, $p=0,242$ ), portal hipertansiyon ve siroz etyolojisi, Child Pugh evresi ve Model for Endstage Liver Disease skoru açısından benzerdi. Endoskopik tedavi her iki grupta da başarıyla yapıldı, endoskopik bant ligasyonuna ait komplikasyon olmadı. Her iki grup arasında tekrar kanama [6'ya (\%30) karşılık 3 $(\% 15,8)$ p=0.640], Adjusted Blood Transfusion Requirement Index skorlar $(0,425$ 'e karşılık 0,421, p=0,918) açısından farklılık saptanmadı. Sonuç: Tek sıra çepeçevre bant ligasyonunun özofagus varis kanamasında daha kullanışh bir yöntem olabileceği sonucuna varılabilir.

Anahtar kelimeler: Endoskopik bant ligasyonu, özofagus varis kanaması, çepeçevre tek sira, hedeflenmiş çoklu-band

\section{GİRIŞ}

Özofagus varis kanaması (ÖVK) sirozun en ölümcül komplikasyonlarından birisidir. Sirozlu hastalarda, tüm üst gastrointestinal kanamaların \%70'i özofagus varislerinin rüptürüne bağlıdır. Siroz nedeniyle gelişen portal hipertansiyon, portosistemik kollaterallerin oluşumuna yol açar; bunlardan en önemlileri de özofageal ve gastrik varislerdir. Varislerin en-
Background and Aims: Esophageal variceal bleeding due to portal hypertension is one of the most lethal complications of cirrhosis. Endoscopic band ligation is the most important option in the treatment of bleeding. It is recommended to start the endoscopic band ligation just above the Z-line, where the varicose veins originate. Hemodynamically problematic most of the time, esophageal variceal bleeding cases are likely to benefit from a shorter upper gastrointestinal endoscopy, with the endoscopic band ligation performed with a small number of bands. This study was planned in order to compare the effectiveness of endoscopic band ligation for varicose veins performed as targeted multi-band versus circumferential single row. Materials and Methods: Thirty-nine consecutive patients admitted to our clinics with esophageal variceal bleeding who underwent one of two different endoscopic band ligation procedures on a random basis were included in the study. In 19 patients, endoscopic band ligation was performed in a single row circumferentially, while in 20 patients, endoscopic band ligation was performed as a targeted multi-band application. In the single row circumferential application, endoscopic band ligation was performed for each column of a single row $2 \mathrm{~cm}$ above the Z-line. For the targeted multi-band application, endoscopic band ligation was applied only to the varicose vein column (or columns) with signs of bleeding, starting from $2 \mathrm{~cm}$ above the Z-line up to the end of that varix(ces). Somatostatin infusion was performed in all patients for 5 days after endoscopic band ligation. Early and late rebleeding and Adjusted Blood Transfusion Requirement Index were evaluated according to Baveno V criteria to assess the treatment success. Results: Both groups were similar in terms of mean age $(54,35$ versus 54,53 years, $p=0,967)$, gender ( $F / M$ ratio $100 \%$ versus $46,15 \%, p=0,242$ ), etiology of portal hypertension and cirrhosis, and Child-Pugh and Model for End Stage Liver Disease scores. Rebleeding rates (6 (30\%) versus 3 (15,8\%), p=0,640) and Adjusted Blood Transfusion Requirement Index scores $(0,425$ versus $0,421, p=0,918)$ did not differ between the two groups. Endoscopic treatment was successful in both groups without any complication of endoscopic band ligation. Conclusions: Single-row circumferential band ligation may be a more practical manner for esophageal variceal bleeding therapy.

Keywords: Endoscopic band ligation, esophageal variceal bleeding, circumferential single row, targeted multi-band

doskopik tedavisinde amaç, varisin obliterasyonu ile varis duvar gerginliğinin azaltılmasıdır; çok sayıda çalışmada özofagus varis kanamasının varis boyutuyla ilişkili olduğu gösterilmiştir $(1,2)$. Bu amaçla kullanılan iki yöntem endoskopik skleroterapi ve endoskopik band ligasyonu (EBL)'dur; göreceli olarak güvenilir ve etkin olması nedeniyle EBL skleroterapiden 
daha çok tercih edilir (3,4). EBL, ilk kez 1989 yllında, Stiegmann ve Goff tarafindan özofagus varis kanamasının tedavisinde kullanıldı. Bu dönemden itibaren, 4-10 bandın yüklü olduğu çoklu band ligatörlerinin de geliştirilmesiyle gastroenteroloji kliniklerinde yaygın olarak kullanılmaktadır (5). EBL, gastroözofageal bileşkeden yukarı yaklaşık 6-8 cm'lik bir segmentte perforan venlerin yerleştiği bölgeye uygulanır (6). $\mathrm{Bu}$ işlemde, elastik bantlar gastroözofageal bileşkeden başlayarak yukarı doğru sarmal bir hat üzerinde yerleştirilir (7). Bu işlem, aktif kanamakta olan veya kırmızı beneklenme veya kamçı işareti gibi kanama işaretleri olan varislere uygulanır. EBL sirasinda bir varis kolonuna bir veya daha fazla sayıda bant uygulanabilir. EBL uygulamasının özofagus distalinden başlanması kuralından hareketle tüm varis kolonlarına sadece tek sıra çepeçevre uygulanabileceğini düşündük (Resim 1). Çoğu zaman hemodinamik açıdan sorunlu olan ÖVK olgularına üst gastrointestinal endoskopide geçirilen sürenin kısa tutulması açısından az sayıda bantla EBL uygulamak daha faydalı olabilir. Tek sıra çepeçevre EBL uygulamasının, hali hazırda yaygın olarak uygulanan kanama bulguları olan varis kolonlarına hedeflenmiş çoklu EBL kadar etkin olabileceğini düşündük. Tek sıra çepeçevre uygulamayla hedeflenmiş çoklu bant ligasyonunun etkinliğini ve güvenilirliğini karşılaştırmak amacıyla kliniğimizde bir çalışma planladık.

\section{GEREÇ ve YÖNTEM}

Mersin Üniversitesi Tip Fakültesi Gastroenteroloji Bilim Dalı'na Ocak 2012-Temmuz 2012 döneminde başvuran ve özofagus varis kanaması saptanan ardışık 39 hasta çalışmaya alındı. Hastalara, hastane dosyalarının son rakamına göre, rastlantısal olarak iki ayrı yöntemle EBL uygulandı. Böylece 19 hastaya çepeçevre tek sıra, diğer 20 hastaya da kolumnar hedeflenmiş çoklu tarzda EBL yapıldı. Çepeçevre tek sıra uygulamada her varis kolonuna $Z$ çizgisinin $2 \mathrm{~cm}$ üzerinden bir kez EBL uygulandı. Kolumnar hedeflenmiş çoklu uygulamada ise sadece büyük boyutlu ve üzerinde kanama işareti olan varis kolonu (veya kolonlarına) Z çizgisinin $2 \mathrm{~cm}$ yukarısından başlanarak alt uçtan yukarı doğru EBL uygulandı (Resim 1). Ardından tüm hastalara Somatostatin 250 mcg/saat hızında intravenöz infüzyonu 5 gün uygulandi. Baveno V kriterlerine göre tedavi başarısı erken ve geç dönemde tekrar kanama, düzeltilmiş transfüzyon gereksinimi indeksi (Adjusted Blood Transfusion Requirement Index: ABRI) açısından değerlendirildi. ABRI değeri, (ABRI) = Toplam uygulanan kan transfüzyonu (ünite) /Son ölçülen Hematokrit- Ilk ölçülen Hematokrit oranıyla hesaplandı (8). Yaş parametresi için tanımlayıcı istatistik olarak ortalama değer verildi. Gruplardaki kategorik yapıdaki parametreler için tanımlayıcı istatistik olarak sayı ve yüzde değerleri verildi. İstatistik anlamlılıkta $\mathrm{p}<0,05$ alındı. Istatistik analizlerde SPSS 11.5 ve MedCalc®v11.0.1 paket programları kullanıldı.

\section{BULGULAR}

Çalışmaya alınan her iki hasta grubunda da yapılan ilk EBL ile başarılı kanama kontrolü sağlandı. Her iki grup arasında, yaş ortalaması açısından farklılık saptanmadı (54,35 yıla karşılık, $54,53$ yll, $\mathrm{p}=0,967)$. Cinsiyet açısından her iki grup benzer bulundu (Kadın 1. Grupta 10 hastaya karşılık, 2. Grupta 6 hasta; erkek 1. Grupta 10 hastaya karşılık, 2. Grupta 13 hasta, $\mathrm{p}=0,242$ ). Portal hipertansiyon (PHT) ve siroz etyolojisi açısindan her iki grup benzer bulundu $(\mathrm{p}=0,785)$; en sik siroz etyolojisi her iki grupta da hepatic C (HCV) idi. Model for End Stage Liver Disease (MELD) skoru açısından benzerdi. Child Pugh evresi açısından her iki grupta da en çok evre B hasta mevcuttu (10 hasta ve 8 hasta) ve evre dağılımı açısından iki grup arasında fark saptanmadı $(p=0,155)$. Her iki grup arasında tekrar kanama açısından fark saptanmadı [6 hastaya (\%30) karşılık 3 hasta $(\% 15,8)$ p=0,640]. Her iki grup arasın-

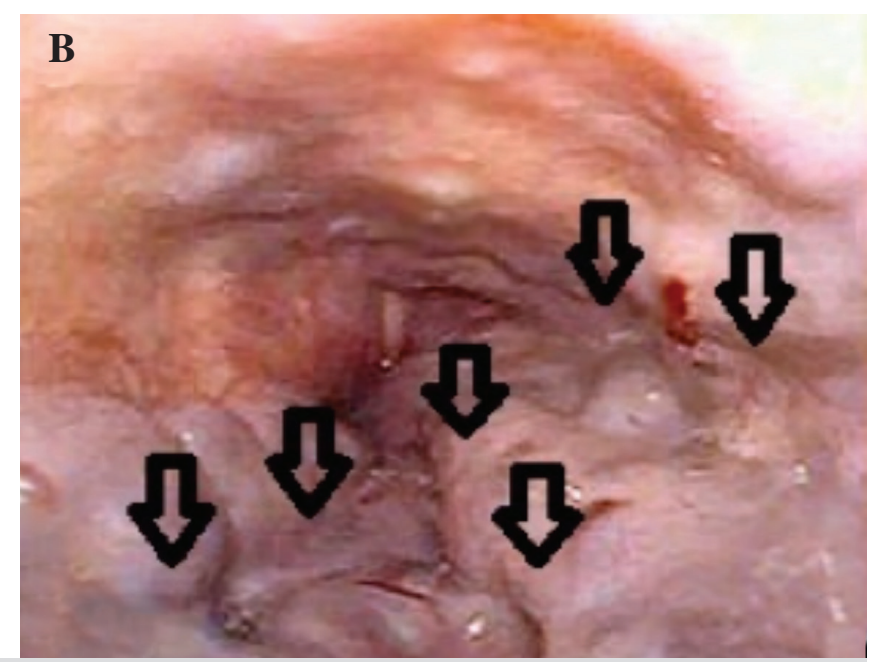

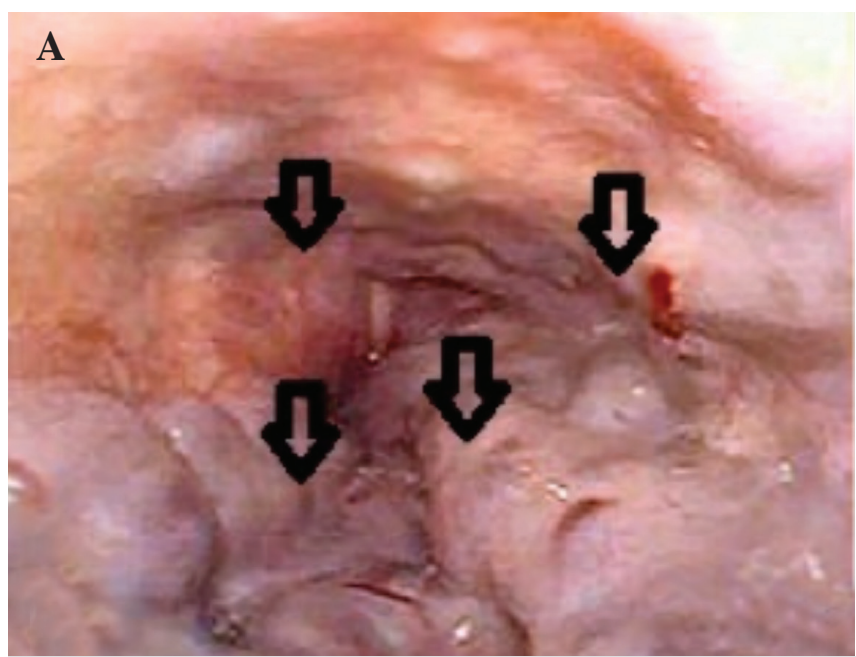

Resim 1. A. Çepeçevre tek sıra uygulamada endoskopik band ligasyonunda (EBL) uygulama noktaları (oklar) B. Hedeflenmiş çoklu uygulamada EBL uygulama noktaları (oklar). 


\section{Tablo 1. Hastaların özellikleri ve tedavi sonuçları}

\begin{tabular}{|c|c|c|c|c|}
\hline & & $\begin{array}{c}\text { Hedeflenmiş } \\
\text { Çoklu } \mathbf{n}=\mathbf{2 0}(\%)\end{array}$ & $\begin{array}{c}\text { Tek Sıra } \\
\text { Çepeçevre } \\
\text { n=19 }(\%)\end{array}$ & p \\
\hline Yaş & & $54,35 \pm 11,68$ & $54,53 \pm 14,77$ & 0,967 \\
\hline \multirow{2}{*}{ Cinsiyet } & Erkek & $10(\% 50)$ & $13(\% 68,4)$ & \multirow{2}{*}{0,242} \\
\hline & Kadın & $10(\% 50)$ & $6(\% 31,6)$ & \\
\hline \multirow{3}{*}{$\begin{array}{l}\text { Child } \\
\text { Sinıfi }\end{array}$} & A & $3(\% 15)$ & $6(\% 31,6)$ & \multirow{3}{*}{0,155} \\
\hline & B & $10(\% 50)$ & $8(\% 42,1)$ & \\
\hline & $\mathrm{C}$ & $7(\% 35)$ & $5(\% 26,3)$ & \\
\hline MELD & & $13,3 \pm 6,39$ & $13.57 \pm 7,57$ & 0,902 \\
\hline \multirow{4}{*}{ Etyoloji } & HBV & $5(\% 25)$ & $3(\% 15,9)$ & \multirow{4}{*}{0,785} \\
\hline & $\mathrm{HCV}$ & $8(\% 40)$ & $7(\% 36,8)$ & \\
\hline & Alkol & $2(\% 10)$ & $2(\% 10,5)$ & \\
\hline & Kriptojenik & $5(\% 25)$ & $7(\% 36,8)$ & \\
\hline \multirow{3}{*}{$\begin{array}{l}\text { Varis } \\
\text { şiddeti }\end{array}$} & $1 / 3$ & $1(\% 5)$ & $3(\% 15,9)$ & \multirow{3}{*}{0,705} \\
\hline & $2 / 3$ & $15(\% 75)$ & $7(\% 36,8)$ & \\
\hline & $3 / 3$ & $4(\% 20)$ & $9(\% 47,3)$ & \\
\hline \multirow{2}{*}{$\begin{array}{l}\text { Fundal } \\
\text { Varis }\end{array}$} & Yok & $16(\% 80)$ & $16(\% 84,2)$ & \multirow{2}{*}{0,658} \\
\hline & Var & $4(\% 20)$ & $3(\% 15,8)$ & \\
\hline \multirow{2}{*}{$\begin{array}{l}\text { Tekrar } \\
\text { kanama }\end{array}$} & Yok & $14(\% 70)$ & $16(\% 84,2)$ & \multirow{2}{*}{0,640} \\
\hline & Var & $6(\% 30)$ & $3(\% 15,8)$ & \\
\hline ABRI & & 0,425 & 0,421 & 0,918 \\
\hline
\end{tabular}

da (ABRI) skorları açısından fark saptanmadı (0,425'e karşıllk, $0,421, \mathrm{p}=0,918)$. Ayrica her iki grupta da ABRI skorları, Baveno V kriterlerine göre kanama kontrolü başarısızlığını gösteren 0,75 sınırından düşüktü, her iki grupta da başarısızlık saptanmadi (Tablo 1).

\section{KAYNAKLAR}

1. Palmer ED, Brick IB. Correlation between severity of esophageal varices in portal cirrhosis and their propensity toward hemorrhage. Gastroenterology 1956;30:85-90.

2. Lebrec D, De Fleury P, Rueff B, et al. Portal hypertension, size of esophageal varices, and risk of gastrointestinal bleeding in alcoholic cirrhosis. Gastroenterology 1980;79:1139-44.

3. Laine L, Cook D. Endoscopic ligation compared with sclerotherapy for treatment of esophageal variceal bleeding: a meta-analysis. Ann Intern Med 1995;123:280-7

4. Sarin SK, Govil A, Jain AK, et al. Prospective randomized trial of endoscopic sclerotherapy versus variceal band ligation for esophageal varices: influence on gastropathy, gastric varices and variceal recurrence. J Hepatol 1997;26:826-32

5. Cárdenas A. Management of acute variceal bleeding: emphasis on endoscopic therapy. Clin Liver Dis 2010; 14: 251-62.

6. Lo GH. The role of endoscopy in secondary prophylaxis of esophageal varices. Clin Liver Dis 2010; 14: 307-23.

7. de Franchis R, Primignani M. Natural history of portal hypertension in patients with cirrhosis. Clin Liver Dis 2001;5:645-63.

\section{TARTIŞMA}

Özofageal varis kanamasının tedavisinde endoskopik tedavi etkin olarak kullanılmaktadır. Etkinliği ve güvenilirliği nedeniyle, akut özofagus varis kanamalarmnda EBL, ilk tercih edilen yöntem olarak endoskopik skleroterapinin yerini almıştır $(9,10)$. EBL sırasında en büyük varis veya kanama işaretleri olan olan varis, ilk bantlanacak varis olmalıdır $(11,12)$. Dekompanse siroz (Child B/C), alkole bağlı siroz etiyolojisi, özofagus varisleri üzerinde kırmızı beneklenme, ilk endoskopide büyük varis varlığı özofagus varislerinin kanama olasilığını arttıran etkenler olarak belirlenmiştir $(13,14)$. Bizim çalışmamizda her iki tedavi grubunda sirozun evresi, etyolojisi ve varis büyüklüğü açısından fark saptanmadı. Benzer özellikteki iki grupta farklı iki yöntem de aynı etkinlikte saptandı. Tek sıra çepeçevre EBL'nin hedeflenmiş çoklu EBL'den daha pratik bir yöntem olarak eş etkinlikte olması bu yöntemin ileride uygulanabileceğini düşündürür.

Bu çalışmada tek sıra çepeçevre EBL grubunda ABRI skorunun $0,75^{\prime}$ in altında saptanması $(0,421)$ bu yöntemin etkin ve güvenli olduğunu göstermektedir. Hemodinamik açıdan çoğu zaman sorunlu olan özofagus varis kanamalı hastalarda tek sıra halinde çepeçevre EBL uygulaması işlem süresini kısaltması açısından faydalı olabilir.

Bu çalışmada EBL'nin çepeçevre tek sıra veya hedeflenmiş çoklu uygulanması arasında, tekrar kanama ve ABRI açısından farklılık saptanmadı. Endoskopik girişimin süresini kısaltması açısından tek sıra çepeçevre yöntem daha kullanışlı olabilir. Bu konuda daha çok çalışmaya ihtiyaç olduğu açıktır.

8. de Franchis R; Baveno V Faculty. Revising consensus in portal hypertension: Report of the Baveno $\mathrm{V}$ consensus workshop on methodology of diagnosis and therapy in portal hypertension. J Hepatol 2010;53:762-8.

9. Laine L, Cook D. Endoscopic ligation compared with sclerotherapy for treatment of esophageal variceal bleeding: a meta-analysis. Ann Intern Med 1995;123:280-7.

10. Stiegmann GV, Goff JS, Michaletz-Onody PA, et al. Endoscopic sclerotherapy as compared with endoscopic ligation for bleeding esophageal varices. N Engl J Med 1992;326:1527-32.

11. Merli M, Nicolini G, Angeloni S, et al. Incidence and natural history of small esophageal varices in cirrhotic patients. J Hepatol 2003;38:266-72.

12. Stiegmann GV, Goff JS, Michaletz-Onody PA, et al. Endoscopic sclerotherapy as compared with endoscopic ligation for bleeding esophageal varices. N Engl J Med 1992;326:1527-32.

13. Zoli M, Merkel C, Magalotti D, et al. Natural history of cirrhotic patients with small esophageal varices: a prospective study. Am J Gastroenterol 2000;95:503-8.

14. Vorobioff J, Groszmann RJ, Picabea E, et al. Prognostic value of hepatic venous pressure gradient measurements in alcoholic cirrhosis: a 10-year prospective study. Gastroenterology 1996;111:701-9. 